\title{
Recruitment into Clinical Trials: Between Rocks and Hard Places
}

\section{Howard Trachtman}

NYU Langone Medical Center, Department of Pediatrics, Division of Nephrology, New York, USA

*Corresponding author: Howard Trachtman, CTSI 227 E 30th Street, NYU Langone Medical Center, Department of Pediatrics, Division of Nephrology, New York, USA, Tel: 646-501-2663; Fax: 212-263-4053; E-mail: howard.trachtman@nyumc.org

Rec Date: Apr 24, 2014; Acc Date: Apr 25, 2014; Pub Date: April 25, 2014

Copyright: $\odot 2014$ Trachtman H. This is an open-access article distributed under the terms of the creative commons attribution license, which permits unrestricted use, distribution, and reproduction in any medium, provided the original author and source are credited.

\section{Clinical Research in Nephrology}

It is no longer a secret that nephrology trails behind all other medical subspecialties in the design and implementation of clinical trials [1]. Moreover, even the subsets of studies that are completed often involve small patient cohorts and are underpowered to achieve their primary objective [2]. These limitations have hindered the development of effective therapeutic agents for most kidney diseases. As a consequence of this global failure to promote an effective clinical research agenda, there have been calls to devise new strategies to foster interest in clinical research and encourage enrollment into clinical trials by patients with kidney disease.

A number of factors that are relevant to kidney disease have been invoked to explain the poor clinical research performance in nephrology. First, kidney disease is often silent and eludes early detection depriving nephrologists of the opportunity to enroll patients at a stage when the disorder has a higher likelihood of responding to treatment. Second, the disease has a greater impact in patients with low socioeconomic and educational status and this may interfere with their comprehension and willingness to participate in clinical research. In addition, it has been suggested that these disadvantaged patient populations with chronic kidney disease may be reluctant to participate in clinical research efforts because of past history of discriminatory and unethical practices and generalized distrust of the medical establishment. Finally, the availability of dialysis and kidney transplantation, which are life-saving procedures, reduces the sense of urgency that surrounds other illnesses and lessens the willingness to consider participation in a trial of a novel therapeutic drug or procedure $[3,4]$.

\section{Strategies to Increase Clinical Research}

There have been recent calls to modify how patients are approached and how clinical research is presented in order to enhance acceptance of research as a vital element in medical care. The questions then ariseare the proposed changes consistent with prevailing standards in bioethics? Should regulatory requirements be modified in order to facilitate the performance of much needed clinical research? Because of the historically inadequate completion of trials in nephrology, those who care for patients with kidney disease may be in a good position to advocate for innovative strategies to improve participation in research.

One approach is to consider participation in clinical research a communal obligation for those with disease. Although the burden of disease does not fall equally on all members of the group, the risk of becoming ill is one we all share. Therefore, one could reasonably draft policies based on the expectation that those who develop an illness for which there is no established treatment, will be obligated to do whatever is in their power to engage with the medical research community to work towards a cure. This approach would consider disease to be as much of a threat to the health and stability of the state as an attack by a foreign nation. In each case, those who are able to serve - young men and women who can enlist in the military and those with untreatable disease - should willingly join in efforts to address the danger for the good of us all. Coercion would be limited because the communal standard would encourage people to move in the direction of participation in research [5]. There are countries in which this communitarian ethic is operative and people behave in accord with this expectation. However, that is not the customary standard in the United States where the tradition of individual autonomy prevails. Under these circumstances, the imperative to join in clinical research and enroll in a trial will still have to be addressed on person-by-person basis [6]. It will not be feasible to design opt out strategies or implement presumed consent procedures because they are unlikely to meet with widespread acceptance in this country.

\section{A Modest Proposal to Encourage Clinical Research}

However, it is unclear if a communitarian approach to research should be totally abandoned. Clinical research occurs on many levels. From the vantage point of the man on the street, clinical research means interventional studies designed to evaluate the efficacy of new treatment or diagnostic procedures. These projects involve sick people and expose them to maneuvers that may cause pain and harm. Under these circumstances, it has been demonstrated that patients individually weigh the likely outcome of their disease and counterbalance this with the potential benefit of the experimental treatment as they deliberate whether or not to enroll in a study [4]. These are the conditions under which most of our discussion of potential risk and benefit are framed. However, a large part of clinical research centers on observational studies that include collection of biosamples. This work is designed to improve our understanding of the disease process. This type of work may yield better biomarkers to enable a diagnosis to be made more precisely, delineate prognosis, and optimize treatment. These projects can involve a wide range of biospecimens including nails, hair, urine, plasma, serum, DNA, and tissue. This represents an escalating scale of invasiveness and potential risk. However, in general, the hazards are far less than in interventional studies. Patients intuitively appreciate this difference and this is reflected in higher rates of participation in observational versus interventional studies [3,7]. It is unlikely that people feel that they place themselves at such great risk if they join observational studies. It is plausible that most people would be willing to adopt a communitarian ethic and provide material to help develop better diagnostics and treatments for the future if it was considered a standard part of their treatment.

Thus, one approach to foster greater acceptance of clinical research is to lower the bar to enrollment into observational studies. A strategy of limited consent could be designed in which patients are informed 
Citation: Howard Trachtman (2014) Recruitment into Clinical Trials: Between Rocks and Hard Places. J Clinic Res Bioeth 5: 1000e101. doi:

Page 2 of 2

that their physician is participating in studies to better understand the cause, outcome and treatment of their disorder. They can opt out. But if they do not, then periodic sampling will be done to apply state-ofthe-art technologies to develop biomarkers for the management of all aspects of their condition. IRB approval would be required but it would be limited in scope and designed primarily to ensure that the sampling protocol is reasonable and safe. It is worth noting that a similar approach has been advocated to distinguish between comparative efficacy studies and clinical investigations into genuinely novel therapeutic interventions. Proposals have been advanced to ease the intensity of IRB oversight, regulatory standards, and detailed informed consent for comparative efficacy research and in pragmatic trials in order to promote greater acceptance of this type of work by patients and physicians $[8,9]$. One could anticipate that by raising the level of participation in observational studies characterized by a very limited risk of harm and by incorporating them into the standard of care at the point of delivery of health, this would make research more relevant to patients and their care givers and integrate it with their overall healthcare. This cultural change might be the stimulus that is needed to encourage more patients and families to view enrollment into interventional clinical trials as an essential element in their care and an enterprise that they would feel comfortable supporting and joining whenever the opportunity presents itself.

\section{References}

1. Strippoli GF, Craig JC, Schena FP (2004) The number, quality, and coverage of randomized controlled trials in nephrology. J Am Soc Nephrol 15: 411-419.
2. Inrig JK, Califf RM, Tasneem A, Vegunta RK, Molina C, et al. (2014) The Landscape of Clinical Trials in Nephrology: A Systematic Review of ClinicalTrials.gov. Am J Kidney Dis 63: 771-780.

3. Ferris M, Norwood V, Radeva M, Gassman JJ, Al-Uzri A, et al. (2013) Patient recruitment into a multicenter randomized clinical trial for kidney disease: report of the focal segmental glomerulosclerosis clinical trial (FSGS CT). Clin Transl Sci 6: 13-20.

4. Gadegbeku CA, Stillman PK, Huffman MD, Jackson JS, Kusek JW, et al. (2008) Factors associated with enrollment of African Americans into a clinical trial: results from the African American study of kidney disease and hypertension. Contemp Clin Trials 29: 837-842.

5. Christensen E (2012) The re-emergence of the liberal-communitarian debate in bioethics: exercising self-determination and participation in biomedical research. J Med Philos 37: 255-276.

6. Chabot C, Shoveller JA, Spencer G, Johnson JL (2012) Ethical and epistemological insights: a case study of participatory action research with young people. J Empir Res Hum Res Ethics 7: 20-33.

7. Gadegbeku CA, Gipson DS, Holzman LB, Ojo AO, Song PX, et al. (2013) Design of the Nephrotic Syndrome Study Network (NEPTUNE) to evaluate primary glomerular nephropathy by a multidisciplinary approach. Kidney Int 83: 749-756.

8. Faden RR, Beauchamp TL, Kass NE (2014) Informed consent, comparative effectiveness, and learning health care. N Engl J Med 370: 766-768.

9. Kim SY, Miller FG (2014) Informed consent for pragmatic trials--the integrated consent model. N Engl J Med 370: 769-772. 